LOS EDUCADORES TRADICIONALES MAPUCHE EN LA IMPLEMENTACIÓN DE LA EDUCACIÓN INTERCULTURAL BILINGÜE EN CHILE: UN ESTUDIO DE CASOS*

\author{
Silvia Castillo Sánchez ${ }^{* *}$ \\ Diego Fuenzalida Orellana*** \\ Felipe Hasler Sandoval ${ }^{* * *}$ \\ Carmen Sotomayor Echeñique ${ }^{* * * * *}$ \\ Claudio Allende González ${ }^{\star \star \star * \star *}$
}

\title{
Resumen
}

El trabajo presenta un estudio de casos realizado en tres escuelas en donde se implementa el Programa de Educación Intercultural Bilingüe (PEIB) en Chile. Se analizaron sus condiciones de implementación y la competencia lingüística e intercultural de los educadores tradicionales. La presente investigación describe a los educadores tradicionales como un grupo con altas competencias y, por tanto, como actores idóneos para llevar adelante este tipo de iniciativas. Además, se releva la importancia de la participación de los directivos, profesores y de la comunidad, tanto indígena como educativa, destacándose el carácter comunitario del proceso.

Palabras claves: educadores tradicionales, mapudungun, competencia lingüística e intercultural.

\section{MAPUCHE TRADICIONAL EDUCATORS IN THE}

\section{IMPLEMENTATION OF THE BILINGUAL INTERCULTURAL EDUCATION: A CASE STUDY}

\begin{abstract}
This paper presents a case study realized in three schools where the Bilingual Intercultural Education Program is implemented. The implementation conditions and the linguistic and intercultural skills of Traditional Educators were studied. This paper describes Traditional
\end{abstract}

* Este artículo forma parte de una investigación denominada “Competencias y percepciones de los Educadores Tradicionales Mapuche, en la implementación del Sector Lengua Indígena Mapuzugun", financiada por el Proyecto FONIDE N: FT11258. Se agradece el financiamiento otorgado por el Proyecto Basal FB0003 del Programa de Investigación Asociativa de CONICYT.

** Chilena. Dra. en Ciencias de la Educación de la Universidad de Santiago de Chile. Académica e investigadora de la Universidad Católica Silva Henríquez, Santiago, Chile. scastillos@ucsh.cl

*** Chileno. Licenciado en Antropología de la Universidad de Chile. Investigador de la Universidad de Chile (CIAE), Santiago, Chile. dfuenzalida@ciae.uchile.cl

**** Chileno. Magíster en Lingüística española de la Universidad de Chile. Académico de la Universidad de Chile, Santiago, Chile. keche.felipe@gmail.com

**** Chilena. Dra. en Pedagogía de la lengua materna de la Universidad Católica de Lovaina. Investigadora de la Universidad de Chile (CIAE), Santiago, Chile. csotomayor@ciae.uchile.cl

******Chileno. Magíster en Políticas Públicas de la Universidad de Chile. Investigador de la Universidad de Chile, Santiago, Chile. callende@ciae.uchile.cl 
Educators as a group with high competences, so they operate as qualified actors to carry out these activities. Furthermore, the relevance of the engagement of the directors, teachers and both indigenous and educative communities is analyzed, standing out the community nature of this process.

Keywords: Traditional Educators, mapudungun, linguistic and intercultural competence.

Recibido: 05-08-2015

Aceptado: 21-01-2016 


\section{Introducción}

Un importante hito en las políticas educativas hacia los pueblos originarios en Chile fue la aprobación del Decreto 280 del 2009 del Ministerio de Educación, que incluye al Sector Lengua Indígena (SLI) para la enseñanza del mapudungun, quechua, aymara y rapa nui, en el currículum escolar nacional. La enseñanza de estas lenguas con carácter obligatorio se inicia en el 2010 para todos los establecimientos con más de un $50 \%$ de estudiantes con ascendencia indígena, porcentaje que disminuye a un 20\% el año 2013.

Considerando el contexto sociolingüístico de las escuelas, el Programa de Educación Intercultural Bilingüe (PEIB) establece diferentes estrategias de focalización, a saber: i) Revitalización ${ }^{1}$, orientada a establecimientos de comunidades con lenguas que presentan una considerable pérdida del patrimonio lingüístico, tales como el kunza del pueblo Likan Antai; ii) Interculturalidad, modalidad que pretende desarrollar talleres en escuelas de zonas de baja vitalidad lingüística, fomentando principalmente las competencias interculturales; iii) Sector de Lengua Indígena (hoy, Asignatura Lengua Indígena), que busca implementar dicho sector curricular de forma paulatina en aquellas escuelas con un $20 \%$ o más de matrícula indígena; y iv) Bilingüismo, estrategia que corresponde a establecimientos ubicados en contextos de alta vitalidad lingüística y que pueden generar una inmersión más profunda en la lengua indígena (PEIB, 2010). Estas estrategias están distribuidas de la siguiente forma en el país:

Tabla I: Distribución de escuelas por región y según estrategia de focalización

\begin{tabular}{|c|c|c|c|c|c|}
\hline \multicolumn{6}{|c|}{ Estrategia de focalización } \\
\hline Región & Interculturalidad & Revitalización & SLI & Bilingüismo & Total \\
\hline $\begin{array}{l}\text { Región de La } \\
\text { Araucanía }\end{array}$ & 6 & 0 & 212 & 2 & 220 \\
\hline Región del Biobío & 4 & 0 & 55 & 0 & 59 \\
\hline $\begin{array}{l}\text { Región de Los } \\
\text { Lagos }\end{array}$ & 1 & 0 & 50 & 0 & 51 \\
\hline
\end{tabular}

1 En este estudio, no se analizó esta estrategia, porque no se evidencia en la lengua mapuche. 


\begin{tabular}{lccccc}
\hline $\begin{array}{l}\text { Región de Los } \\
\text { Ríos }\end{array}$ & 2 & 0 & 35 & 0 & 37 \\
\hline $\begin{array}{l}\text { Región de } \\
\text { Magallanes }\end{array}$ & 1 & 11 & 1 & 0 & 13 \\
\hline $\begin{array}{l}\text { Región } \\
\text { Metropolitana }\end{array}$ & 27 & 0 & 0 & 0 & 27 \\
\hline Total & 41 & 11 & 353 & 2 & 407 \\
\hline
\end{tabular}

Fuente: Sotomayor, Allende, Fuenzalida, Hasler y Castillo, 2014

Uno de los aspectos claves en la implementación de las cuatro estrategias de focalización mencionadas es la "dupla pedagógica", constituida por el profesor mentor (docente de aula) y por el educador tradicional. El primero aporta el conocimiento de la cultura escolar y el saber pedagógico; el segundo, los saberes tradicionales de su cultura y su lengua.

Los antecedentes del educador tradicional se encuentran en el Programa Orígenes, en el que era denominado "asesor cultural comunitario". Su labor estaba centrada en el apoyo a proyectos de los establecimientos educativos focalizados por este programa y su ingreso se debió a la falta de profesores hablantes de lengua indígena. Este asesor era elegido y validado por los padres de familia, autoridades tradicionales y funcionales de la comunidad. En gran parte de los casos, el asesor era reconocido como "sabio", es decir, una persona que posee conocimientos sobre la lengua y la cultura indígena (Quidel, 2006).

El Ministerio de Educación registra un total de 323 educadores tradicionales en todo Chile², de los cuales 275 son del pueblo Mapuche ( $85 \%$ del total). Estos se ubican preferentemente en las regiones VIII, IX y X, siendo la segunda la que concentra el mayor número de educadores registrados, con un $49 \%$. Una encuesta reciente (Sotomayor y otros, 2014) a 208 educadores tradicionales mapuche arrojó que un $63 \%$ eran mujeres y un $37 \%$, hombres.

Respecto a la competencia lingüística de estos educadores, Acuña (2012) y Sotomayor y otros (2014) concluyen que existen diferencias entre los educadores, a nivel regional, siendo las regiones del Biobío, Araucanía

2 Datos actualizados al año 2013, sin contabilizar los educadores que trabajan en proyectos derivados de la Ley de Subvención Escolar Preferencial (SEP). 
y Metropolitana las que registran una mayor competencia declarada y las regiones de Los Lagos y de Los Ríos, la menor.

Considerando que la focalización del PEIB se ha ampliado a nuevos sectores, incluyendo zonas urbanas y de baja vitalidad lingüística de mapudungun, resulta importante conocer las diferencias en las condiciones de implementación de cada estrategia, así como las características centrales que deberían tener los educadores tradicionales en el ejercicio de la docencia de la lengua mapuche, tales como sus competencias lingüísticas e interculturales.

Este artículo busca indagar en estos aspectos a partir de un estudio de casos de tres educadores tradicionales que implementan el sector en las tres estrategias de focalización impulsadas por el PEIB para escuelas con población mapuche, a saber: Interculturalidad (Región Metropolitana), Bilingüismo y Sector de Lengua Indígena (ambas de la Región de la Araucanía).

\section{Marco de referencia}

Algunos autores (Acuña, 2012; Loncon y Martínez, 2011; Sotomayor y otros, 2014) destacan la importancia central que tienen tanto las condiciones de implementación como las competencias de los educadores tradicionales para el desarrollo del PEIB en Chile. A continuación se desarrollan los principales conceptos relacionados con estas temáticas.

\subsection{Condiciones de implementación}

En este artículo, se denomina "Condiciones de implementación del SLI" al contexto comunitario, recursos físicos y humanos con los que cuenta cada establecimiento, trayectorias de iniciativas interculturales y actitudes de los actores hacia la enseñanza del mapudungun en la escuela. Este último punto es de especial interés pues, tal como menciona García Marcos (1993), las actitudes hacia la lengua pueden influir en los procesos de conservación y desplazamiento de dos o más lenguas. En este sentido, pueden determinar los dominios de uso y funciones comunicativas de los códigos, así como también los procesos de adquisición y aprendizaje de una lengua. Por esto, se sostiene que una actitud favorable de los actores hacia la lengua y el SLI sería fundamental para una positiva implementación del programa y, a la inversa, entorpecería sus avances. 
Al respecto, Treviño y otros (2012) señalan que el apoyo que los directores de las escuelas focalizadas brindan a este nuevo sector curricular se relaciona positivamente con la implementación del SLI.

\subsection{La competencia lingüística}

La competencia comunicativa (Hymes, 1971) es entendida como el conjunto de habilidades y conocimientos que permiten que los hablantes de una comunidad lingüística puedan comprenderse (la lengua como práctica social). En el caso de este estudio, se refiere al conocimiento que los educadores tradicionales tienen del mapudungun (competencia lingüística) y a su uso.

Por otra parte, la competencia lingüística en el caso de los educadores tradicionales mapuche necesariamente se enmarca dentro del estudio del bilingüismo, tanto de estos educadores como de la población mapuche en general. Así, desde un punto de vista individual, el bilingüismo atiende a la realidad cognitiva del sujeto, al nivel de bilingüismo alcanzado, a sus componentes actitudinales y a sus consecuencias en la autoestima de los individuos (Grosjean, 1982). Mientras que desde una perspectiva centrada en la comunidad en la que se inserta, se considera la situación social de contacto entre la lengua dominante y la lengua minorizada, con especial énfasis en las condiciones de poder que describen y explican la manera en que este bilingüismo tiene lugar (Salas, 2006; Zúñiga, 2007 y Gundermann y otros, 2008, 2009).

Evidencias de lo anterior se encuentran en Gundermann y otros $(2008,2009)$, quienes relevan la reubicación desventajosa en el sistema de relaciones interétnicas sufrida por el pueblo Mapuche luego de la ocupación de la Araucanía, la que lo transformó en un grupo reducido y sujeto a la dominación económica y social chilena. Este proceso de "integración" tuvo como consecuencia una progresiva descomposición socio-demográfica de la sociedad mapuche, caracterizada por la migración forzada de la población hacia los centros urbanos. En consecuencia, el mapudungun pasó de ser la lengua predominante de la sociedad mapuche a estar en una situación de diglosia con el español. Asimismo, los autores enfatizan que un modelo diacrónico y dinámico permite explicar por qué el nivel de bilingüismo mapuche-español varía diatópicamente en el territorio tradicional. 


\subsection{Competencia Intercultural}

El concepto de competencia intercultural, para efectos del presente estudio, se entenderá desde una dimensión comunicativa, y será definida como "el conjunto de habilidades cognitivas y afectivas para manifestar comportamientos apropiados y efectivos en un contexto cultural determinado, que favorezcan un grado de comunicación suficientemente eficaz" (Vilà, 2003, p. 2). Estos conceptos han sido empleados en el marco de las interrelaciones en el sistema escolar, por ejemplo, entre estudiantes, entre docentes y estudiantes, o entre los propios docentes.

A partir de esta definición, Vilà (2003) define tres dimensiones principales de la competencia comunicativa intercultural: i) competencias cognitivas, esto es el conocimiento, comprensión y conciencia de todos aquellos elementos culturales y comunicativos tanto propios como de otros, que promueven una comunicación efectiva; ii) competencias afectivas, es decir, la capacidad de emitir respuesta positivas y controlar emociones que puedan perjudicar el proceso comunicativo; y iii) competencias comportamentales, referidas al conjunto de habilidades verbales y no verbales que evidencian una adaptación de la conducta que favorezca comunicarse de forma eficaz. Lo anterior implica que, para desarrollar una competencia comunicativa intercultural, las personas debieran desarrollar conocimientos, actitudes y capacidades.

En Chile, Loncon y Martínez (2011) ponen de relieve estas características en el marco de la implementación de la EIB y del SLI. Para los autores, existen ciertos componentes principales de la competencia intercultural: i) conocimientos orientados a la lengua indígena, a la otra cultura y a una perspectiva de la cultura desde la diversidad; ii) habilidades vinculadas a la capacidad de establecer relaciones entre la cultura de origen y la otra cultura, empleando diversas estrategias para abordar con eficacia las problemáticas surgidas en contextos conflictivos y potenciando el desarrollo de la sensibilidad cultural; de igual modo, refiere a la capacidad de superar los prejuicios frente al otro y combatir la discriminación, el racismo y los procesos de homogeneización; iii) actitudes ligadas a la dimensión socio-afectiva, las cuales relevan la importancia de la empatía en las aulas interculturales, fomentan el respeto a la diversidad cultural y contradicen políticas de marginación hacia los pueblos originarios. 


\section{Metodología}

Para indagar en las competencias lingüísticas e interculturales de los educadores tradicionales mapuche, así como en las condiciones de implementación de dicha asignatura en las tres estrategias de focalización, se realizó un estudio de casos en tres establecimientos educacionales del país. Los estudios de casos forman parte de una investigación mixta (cualitativa y cuantitativa) que incluyó la construcción y aplicación de una encuesta a 208 educadores tradicionales mapuche (Sotomayor y otros, 2014), que consideró las mismas dimensiones descritas en el marco de referencia.

Se definió un caso instrumental (Gundermann y otros, 2011) para cada una de las tres estrategias de focalización ya mencionadas. Se estableció como criterio de selección que cada establecimiento implementara algunas de las modalidades definidas desde el año 2010, y que existiera una buena disposición de la escuela y del educador tradicional para realizar el estudio.

En cada caso se realizaron dos entrevistas semiestructuradas al educador tradicional, una al inicio del estudio y otra luego de haber observado una de sus clases, ambas de acuerdo a una pauta diseñada para ello. Además, se entrevistó al director y/o jefe técnico del establecimiento, al profesor mentor y a dos apoderados. Finalmente, se realizó una entrevista grupal con estudiantes de un nivel $\left(1^{\circ}\right.$ a $4^{\circ}$ básico) donde el educador desempeñara sus funciones, a fin de conocer sus percepciones acerca de la enseñanza del mapudungun en la escuela (ver Tabla II). En base a los objetivos del estudio, se elaboraron protocolos de entrevistas individuales o grupales (estudiantes) para cada uno de los actores mencionados ${ }^{3}$. La técnica de análisis de los instrumentos utilizada fue "teoría fundamentada" (Strauss y Corvin, 2002).

3 Todos los instrumentos utilizados están disponibles para quien los solicite a los autores. 
Tabla II: Estudio de casos. Escuelas investigadas y entrevistas realizadas

\begin{tabular}{|c|c|c|c|c|c|c|c|}
\hline Región & Caso & $\begin{array}{l}\text { Estrategia de } \\
\text { focalización }\end{array}$ & $\begin{array}{l}\text { Educador } \\
\text { tradicional }\end{array}$ & Directivos & $\begin{array}{l}\text { Profesor } \\
\text { Mentor }\end{array}$ & Aprobados & $\begin{array}{c}\text { Estudiantes } \\
\text { (Entrevista } \\
\text { Grupal) }\end{array}$ \\
\hline $1^{\circ}$ Metropolitana & $\begin{array}{l}\text { Escuela } \\
\text { municipal } \\
\text { urbana, comuna } \\
\text { de La Pintana } \\
\end{array}$ & Interculturalidad & 1 & 2 & 1 & 2 & $4\left(5^{\circ}\right)$ \\
\hline $2^{\circ}$ Araucanía & $\begin{array}{l}\text { Escuela } \\
\text { municipal } \\
\text { rural, comuna } \\
\text { de Padre de las } \\
\text { Casas, }\end{array}$ & $\begin{array}{l}\text { Asignatura } \\
\text { Lengua Indígena }\end{array}$ & 1 & 1 & 1 & 1 & $10\left(4^{\circ}\right)$ \\
\hline \multirow[t]{2}{*}{$3^{\circ}$ Araucanía } & $\begin{array}{l}\text { Escuela } \\
\text { particular } \\
\text { subvencionada } \\
\text { rural, comuna } \\
\text { de Temuco }\end{array}$ & Bilingüismo & 2 & 2 & 1 & 1 & $8\left(3^{\circ}\right.$ y $\left.4^{\circ}\right)$ \\
\hline & & & 4 & 5 & 3 & 4 & 22 \\
\hline
\end{tabular}

Fuente: Informe Fonide n ${ }^{\circ}$ FT11258

\section{Resultados}

A continuación, se presentan los resultados del estudio de casos vinculados a las condiciones de implementación, competencia lingüística y competencia intercultural de los educadores tradicionales de las tres escuelas seleccionadas.

\subsection{Condiciones de implementación}

La escuela con estrategia de bilingüismo (en adelante EB) se ubica en la comuna de Temuco, región de la Araucanía. Fue creada en el año 2000 con un enfoque comunitario-participativo en zona rural, multi e intercultural y de excelencia educativa.

Las primeras acciones sobre interculturalidad abordaron la integración curricular de la cultura y lengua mapuche a partir de la participación de un kimche (sabio), quien trabajaba realizando adecuaciones curriculares para la escuela. En el año 2013, después de generar su propio proyecto, se incorpora al PEIB bajo la modalidad ya mencionada, creando lineamientos contextualizados a la realidad local.

Desde su fundación, existe una actitud favorable de la comunidad hacia la enseñanza del mapudungun y la asignatura de Lengua Indígena. Así, por ejemplo, los apoderados valoran el papel autoafirmativo de la escuela en relación con la identificación mapuche por parte de los niños y el uso de la lengua indígena. 
La dotación docente de planta está constituida por nueve profesores; de ellos, cinco son mapuche. Quienes llegan a formar parte del establecimiento son informados del valor que ocupa la revitalización de la lengua mapuche, debiendo comprometerse a aprender mapudungun en caso de no hablarlo. Las particulares características de la escuela exigen docentes con un alto compromiso, pues sus acciones no se agotan en el aula. La diversidad de actividades, como trawün (reuniones) territoriales, encuentros culturales, entre otros, demandan más tiempo de lo explicitado en términos contractuales. La siguiente cita ilustra lo señalado:

"La persona que llega a trabajar a esta escuela debe saber dónde queda; es [un establecimiento] distinto, hay un compromiso distinto, hay actividades distintas, actividades culturales que en otros colegios no se hacen, donde tú cumples tu horario y te vas, (...) por lo tanto, uno tiene que tener la mejor disposición y decir 'iya vamos!', y también hay un cansancio, un agotamiento, pero cuando tú ves a los pichikeche [estudiantes] que te dicen 'lamngen, mari mari' [hermanos(as), hola] te das por satisfecha con el esfuerzo." (Profesora mentora, EB).

En un contexto muy similar, pero con una implementación distinta, la escuela con estrategia de asignatura Lengua Indígena (en adelante ELI) es de administración municipal y se encuentra en el sector rural de Maquehue, comuna de Padre de las Casas, región de la Araucanía. Su ubicación, al interior de una comunidad mapuche, explica que el 98\% de sus estudiantes son pertenecientes a dicho pueblo originario. El establecimiento imparte desde educación parvularia a octavo básico, con cursos combinados en primero, segundo, tercero y cuarto básico.

La escuela fue fundada el año 1973 con ayuda de la comunidad. Paulatinamente, fue aumentando la cantidad de estudiantes y el prestigio entre las comunidades aledañas, sobre todo por sus buenos resultados educativos en los últimos años. De hecho, en 2008, la escuela tuvo el mejor puntaje SIMCE ${ }^{4}$ de la comuna (298 en lenguaje y 274 en

4 El SIMCE (Sistema de Medición de la Calidad de la Educación) es una prueba estandarizada implementada a nivel nacional. Ver: www.simce.cl. 
matemática). Según el Proyecto Educativo Institucional (PEI), una de sus metas más importantes es mantener la excelencia académica, priorizando sus esfuerzos en el área de gestión curricular.

Sobre su trayectoria de iniciativas interculturales, el establecimiento se ha sumado a todos los programas escolares originados por el Ministerio de Educación para la población mapuche. Antes de implementar la asignatura, la escuela se integró al Programa Orígenes, elaborando un plan y programa de estudios propio ligado al fortalecimiento de la cultura mapuche, iniciativa discontinuada una vez que la entidad estatal dejó de enviar recursos en el año 2009. Además de estas acciones promovidas por organismos externos, la escuela se vincula con la comunidad indígena, realizando trawün (reuniones) y celebraciones tradicionales, tales como el wiñol tripantü (año nuevo). Sin embargo, pese a lo anterior, los apoderados manifestaron cierta reticencia inicial hacia la enseñanza del mapudungun en la escuela, debiendo intervenir el director del establecimiento, quien convenció a la comunidad de que la iniciativa sería un aporte en términos pedagógicos:

"A nosotros nos costó para incorporar la lengua indígena en el currículum, porque los apoderados nuevos preguntaban ¿¿Para qué va a servir? ¿Qué va a pasar? ¿Se va a oficializar esa lengua? ¿Va a entrar en la evaluación? ¿Va tener un promedio?' Y claro, cuando nosotros le aclaramos la situación, que esto se va colocar en el currículum del Ministerio y va a llegar a ser oficial... A ellos les costó aceptar esa situación decían 'no, que mi niño está muy bien hablando en castellano', nacen y comienzan a hablar en castellano y se pierde la lengua mapuche porque de nada sirve (...) Ahora, como ya llevamos años, los apoderados están bien interesados en la lengua indígena." (Director, ELI).

La escuela cuenta con trece docentes que, en su mayoría, no son indígenas y no hablan el mapudungun. No obstante, el director y la jefa técnica son mapuche y hablan la lengua indígena. Esta condición genera un importante respaldo a todas las actividades que liguen a la escuela con la cultura mapuche.

En materia de infraestructura, el establecimiento presenta amplias áreas verdes y espaciosas salas con adecuada iluminación. A diferencia 
de la otra escuela investigada en la región, esta no cuenta con espacios específicos vinculados a la cultura mapuche, salvo elementos decorativos en las salas y pasillos. Pese a que hay una ruka de la comunidad indígena frente al establecimiento, esta no se utiliza para actividades escolares.

Un caso distinto a los anteriores lo constituye la escuela con estrategia intercultural (en adelante EI) ubicada en la población El Castillo, comuna de La Pintana, Santiago. Los objetivos declarados del establecimiento están vinculados al desarrollo integral de sus estudiantes y a la excelencia académica. A diferencia de las otras escuelas estudiadas, la enseñanza de la lengua y cultura mapuche no está dentro de sus prioridades, a pesar de que se reconoce que un $10 \%$ de la matrícula es mapuche, aproximadamente 30 estudiantes.

La incorporación de la educadora tradicional se concreta a través de una iniciativa del Municipio, el año 2010. Antes de esto, no hubo otros proyectos tendientes a involucrar la cultura indígena en la escuela. Durante estos años, la educadora ha ocupado un lugar marginal dentro de la escuela, pero paulatinamente ha logrado encontrar un espacio y validar su actividad frente a la comunidad educativa. El inicio de su trabajo se caracterizó por el rechazo de parte de la mayoría de los profesores y profesoras de la escuela:

“Me costó estar acá, me costó tomar este espacio. Recibí portazos, que no sabíamos nada, qué nos van a enseñar. A mí me tocó duro. Al comienzo los profesores no me miraban, no me saludaban, yo era un bicho raro acá (...) al principio yo me sentaba al final [de la sala], a veces ni me sentaba, parecía un paco, un carabinero, no tenía dónde apoyar mi bolso ni lo que traía. Era para mí muy doloroso, por ser mapuche no tuve espacio." (Educadora, EI).

La situación descrita se ha revertido gradualmente por dos factores: la educadora ha podido demostrar a la comunidad escolar su competencia en la enseñanza del mapudungun y en el conocimiento de su cultura y, a fines del año 2013, el cambio en la dirección del colegio permitió incorporar el taller intercultural dentro del proyecto institucional, otorgándole al establecimiento un sello distintivo.

En relación a la infraestructura, el establecimiento fue construido entre los años 2002 y 2003, y cuenta con un diseño singular dentro 
de un contexto urbano de gran homogeneidad. Si bien dentro de esta espacialidad no hay lugares ligados directamente a la cultura mapuche, hay pinturas alusivas a dicho pueblo originario en los muros interiores de la escuela.

\subsection{Competencia lingüística}

En relación a la competencia lingüística, la EB tiene requisitos rigurosos para incorporar a los educadores. Estos deben ser hablantes fluidos del mapudungun y poseer vastos conocimientos de su cultura. La adquisición del mapudungun como lengua materna aparece como un elemento común y relevante en los dos educadores que trabajan en la escuela. A pesar de que el colegio está inserto en una comunidad mapuche, la lengua materna de los estudiantes es el castellano y su dominio del mapudungun es bajo, lo que es coherente con la percepción de escasa competencia de esta lengua entre los actores escolares.

En lo concerniente a las habilidades específicas del mapudungun, la oralidad es la competencia discursiva que más se utiliza en la comunicación habitual de los educadores. La escritura y la lectura están menos desarrolladas. Por ejemplo, comprenden la lectura, aunque con dificultades asociadas a los grafemarios. Señalan que los grafemas, al no estar escritos de la misma forma en la que se pronuncian, dificultan la comprensión. De igual modo, los educadores pueden discutir acerca de elementos más específicos de la lengua, como la pronunciación y las variantes dialectales.
"Yo creo que nos comunicamos como mapuche, porque tenemos una sola lengua, pero se habla de diferente acentuación (...) yo tengo un peñi [hermano entre hombres], que es de Puren, entonces yo lo bromeo: 'hermano, peñi, para qué nos vamos a pelear por la $\mathrm{V}$ o por la $\mathrm{F}^{\prime}$, porque ellos dicen veley [bien] y yo digo feley". (Educador, EB).

A pesar del bajo uso del mapudungun en el contexto sociolingüístico de la EB, percibido por los educadores, el empleo de esta lengua alcanza aproximadamente el $80 \%$ en una clase de lengua indígena, y se utiliza de forma básica ${ }^{5}$ en el resto de las asignaturas.

5 El uso básico del mapudungun en la sala de clases alude a los conocimientos protocolares como saludos, despedidas y vocabulario básico. 
Una clase habitual de mapudungun comienza en la ruka con la llegada de la profesora y sus estudiantes, quienes son recibidos por el educador tradicional. Una vez ubicados, el longko del curso, acompañado del werken (mensajero), dirige el llellipun, rogativa que consiste en solicitar permiso para comenzar la clase. Después de esta, se realiza el saludo (chalin) en mapudungun por parte de ambos docentes. Los niños responden también en lengua mapuche; primero lo hacen colectivamente y, luego, de manera individual. Dicho saludo incluye el nombre, el estado anímico, la procedencia (nombre del lof) y la edad. Posteriormente, acompañado del mate ${ }^{7}$, se destina un espacio para el nütramkan (conversación), cuya finalidad se vincula con la resolución de problemas al interior del curso. Tanto las intervenciones del educador como las de la profesora mentora son en mapudungun y solo cuando estos perciben que no se comprendió el discurso, la explicación se realiza en castellano. La clase finaliza después de bastante ejercitación en términos orales. Se fomenta el diálogo permanentemente y se incentiva a los estudiantes a responder en mapudungun.

En la ELI, la competencia lingüística de la educadora tradicional fue un requisito importante para su elección, presentando regulaciones claras y exigentes sobre el dominio del mapudungun. Ello se grafica en la comprobación de sus competencias en asamblea de apoderados:

"Fuimos cinco candidatos, entre ellos me nombraron a mí que podía pasar y uno tenía que presentarse en mapuche. $\mathrm{Y}$ entonces como yo soy hablante, me presenté, pero todo en nuestro idioma." (Educadora, ELI).

Según el director y la educadora tradicional, la cantidad de apoderados hablantes de mapudungun es reducida y pocos presentan una elevada competencia en esta lengua. En parte, esto se debe a que la actual generación de padres del establecimiento no adquirió el mapudungun como lengua materna, a diferencia de lo que ocurre con la educadora, que aprendió dicha lengua al mismo tiempo que el castellano.

6 Longko significa cabeza en mapudungun, pero en este caso se utiliza para denominar al líder dentro de una comunidad tradicional mapuche.

7 En reuniones y conversaciones domésticas, se suele tomar mate como parte de una práctica cultural mapuche. 
Respecto de las habilidades específicas del mapudungun, la educadora de esta escuela presenta mayores competencias en oralidad y comprensión. En lo relativo a la escritura, ella escribe como suena la palabra a partir del alfabeto castellano. Si bien hay un reconocimiento de esta situación, ella indica que escribir el sonido de la palabra tiene un sentido práctico para la enseñanza, pues con ello no confunde a los estudiantes. En este sentido, no manifiesta preocupación por la diversidad de grafemarios existentes.

Pese a que la educadora presenta una elevada competencia en mapudungun, ello no se traduce en su uso en el aula. Solo se evidencia en los saludos protocolares, en la presentación del tema de la clase y el objetivo, primero hablado en mapudungun y luego traducido al castellano. El objetivo está escrito en la pizarra en castellano y debe ser anotado en el cuaderno de la asignatura. Asimismo, se describe el contenido de la clase, expresando en mapudungun los términos que buscan ser aprendidos para luego ser traducidos al castellano. Cabe destacar que la educadora realiza clases solo en los cursos combinados, por lo que los contenidos se repiten, hecho que desmotiva a los estudiantes. Además de los temas abordados en la clase, los niños usan el mapudungun en los saludos y despedidas, pero no realizan más interacciones comunicativas en esta lengua con la educadora. Están habituados a escuchar el mapudungun primero y luego la explicación en español. La situación descrita solo se observa en la clase de lengua mapuche; el resto de las asignaturas no incorpora el mapudungun ni siquiera en un uso básico.

El último caso, correspondiente a la EI se presenta en un contexto sociolingüístico donde la vitalidad es prácticamente nula. Los miembros de la comunidad educativa no hablan la lengua ni la comprenden. Esta situación, si bien ha sido diagnosticada por la educadora, no la desmotiva a incorporar la enseñanza de la lengua y la cultura mapuche.

A diferencia de los educadores en contexto mapuche y rural, esta educadora fue elegida por su experiencia en este tipo de trabajos. Sus competencias lingüísticas y su adquisición de la lengua no fueron sometidas a validación por parte de la comunidad escolar, sino que fue su trayectoria la que definió su incorporación en la escuela. Además, en contraste con los otros educadores, durante muchos años fue hablante pasiva de mapudungun. Su uso funcional en el espacio escolar le 
permitió recuperar la fluidez y, actualmente, posee una competencia alta en la lengua.

Respecto a las habilidades propias del mapudungun, la oralidad aparece como una estrategia habitual en sus clases, pero esto no impide el empleo de otros recursos lingüísticos. La educadora utiliza con frecuencia la escritura como apoyo a la enseñanza de nuevas palabras y asume que ella misma ha desarrollado esta habilidad por iniciativa personal y con la práctica de las clases.

Elusodel mapudungunen la sala es básico, limitándose principalmente al saludo y despedida. Un uso más amplio del mismo se ve obstaculizado por la escasa comprensión de los niños cuando la oyen hablar en lengua mapuche. Pese a esto, ella se esfuerza por enseñarles palabras vinculadas a los diferentes contenidos de aprendizaje. Asimismo, cabe destacar que el empleo del mapudungun se incrementa cuando la educadora comparte ül (canciones) con los niños.

\subsection{Competencias Interculturales}

En la EB hay dos educadores tradicionales: uno de ellos es originario de la zona donde se ubica la escuela y el segundo proviene de otra comunidad. Tanto para la directora como para la profesora mentora, ambos han demostrado un gran conocimiento de la cultura y las tradiciones mapuche, y entre ellos dialogan acerca de las particularidades locales que tienen ciertas prácticas que se realizan en la comunidad y que buscan ser replicadas en la escuela. Gracias a las favorables condiciones de trabajo que presentan y a la validación de sus conocimientos, es posible traspasar, de forma tradicional, dichas prácticas culturales mapuche a los estudiantes.

Los objetivos de la escuela, que apuntan a rescatar y fortalecer la cultura mapuche, se han visto materializados en todas las asignaturas y de manera más específica en el SLI, que se desarrolla en un espacio particular (la ruka) y promueve unas relaciones sociales propias de la cultura mapuche al interior del establecimiento. Esta situación configura una interculturalidad entre lo mapuche y lo no mapuche que se incorpora al concepto de "institución escolar". En este diálogo, los educadores aceptan la estructura escolar y algunos de sus recursos, como la tecnología; pero también discuten constantemente la educación no 
mapuche, segmentada en asignaturas y con una racionalidad diferente a su cultura. La siguiente cita señala lo anterior:

“El mapuche tiene su kimün, 'conocimiento', al revés. El mapuche no tiene un kimün cuadrado como esta esquina de esta casa, no es así. El mapuche tiene un kimün redondo, en forma de círculo, entonces eso es lo que nosotros cambiamos ahí con la lamngen María Isabel [profesora mentora]. Hay que ver si le torcemos la mano, pero no de golpe, porque hay que pasar los planes y programas." (Educador, EB).

Pese a la amplia aceptación del mapudungun y de los educadores tradicionales en la escuela, algunos apoderados evangélicos continúan renuentes a esta enseñanza. El establecimiento se apoya en la excelencia académica para lidiar con estas críticas, indicando que el reforzamiento cultural mapuche no va en detrimento del desarrollo de habilidades educativas convencionales.

Diferentes son las competencias interculturales de la educadora tradicional de la ELI, que ha sido descrita por los actores educativos como una gran conocedora de la cultura y la lengua mapuche, aspectos que motivaron su elección para el cargo. No obstante, el director indicó que para ejercer la docencia aún le falta dominio sobre elementos educativos no mapuche predominantes en la lógica de enseñanza de esta escuela, razón por la cual ha promovido que la educadora termine su enseñanza media y, de esta forma, pueda vincular ambos tipos de saberes.

La educadora tradicional señala que no ha tenido la necesidad de recurrir a actitudes que promuevan un entendimiento entre las culturas o solucionar problemas relativos a este aspecto, principalmente porque, en el establecimiento, casi la totalidad de los alumnos provienen de comunidades mapuche. Por este motivo, la educadora se aboca fundamentalmente a reforzar prácticas y protocolos mapuche con los alumnos, con especial interés en fortalecer su autoestima, tal como se menciona en el relato a continuación:

"Yo les digo que como somos mapuche tenemos que sentirnos orgullosos, no podemos avergonzarnos, yo les digo a los niños: 'tú, si ves una persona de edad tienes que saludarlo en mapuche'. Entonces, ¿qué pasa si uno le habla en castellano? Ellos se ofenden. Entonces tienen que hablarles en mapuche, 
saludarlos mari mari chachay [hola, abuelito], no les cuesta hablar y ustedes como mapuche no tienen que avergonzarse de nuestro idioma." (Educadora, ELI)

En este escenario de homogeneidad cultural, y con una educadora que permanece en la escuela solo cuando realiza clases, sus habilidades interculturales no han sido resaltadas, en el sentido de generar un diálogo o debate intercultural como ocurre en la escuela EB, limitándose su desempeño principalmente al traspaso de contenido de la cultura mapuche a niños mapuche.

Muy distinta es la situación de la educadora tradicional de la EI. En principio, los profesores que le han brindado un espacio se han sorprendido por el vasto conocimiento que ella tiene sobre la cultura mapuche y la diversidad de estrategias que utiliza para enseñarlo. Todos estos aspectos enmarcados en la dimensión cognitiva.

Sin embargo, las dimensiones afectivas y conductuales de su competencia intercultural son las más destacadas, pues a diferencia de sus pares de la región de la Araucanía, la educadora tradicional ha debido enfrentar situaciones de evidente discriminación étnica entre sus alumnos:

“Un niño discriminó a otro y me ardía no sé hasta dónde. Cuando terminó, me queda mirando y yo digo: ‘`Ven a mí a tocarme, yo también soy india! ¿Me ves con plumas? ¿Me ves desnuda?' El niño no hallaba dónde meterse (...) y al final ese niño a los días me pidió disculpas (...) Esos niños discriminados estaban así [hace gesto de la cabeza inclinada sobre las manos], con miedo. Y esa vez les dije: 'saben que de hoy día no quiero ver a ni un niño que trate mal a este niño, ellos son dueños de la tierra; gracias a estos indios que somos -les dije yo- usted está aquí, si no quizás dónde estarían. Esta tierra les corresponde a los mapuche, tienen que estudiar un poquito la historia de Chile. Pero ese niño, esos niñitos después fueron mi apoyo (...) agarraron fuerza, nunca más agacharon la cabeza." (Educadora, EI).

Como se aprecia, la educadora se ve desafiada por situaciones en que su posición y la de la cultura mapuche dentro de la escuela son puestas 
en cuestión, por lo que debe desarrollar habilidades interculturales para persistir en su actividad. En este sentido, ha tenido que dialogar constantemente con todos los actores para justificar su presencia en la escuela.

\section{Discusión}

A continuación se analizan y discuten los aspectos más significativos de los resultados anteriormente presentados.

\subsection{Condiciones de implementación}

Respecto a esta dimensión, el estudio de casos aportó luces en relación a los elementos que influyen en una positiva implementación de programas de este tipo. Se encontró que una alta densidad de población mapuche en el entorno de la escuela y una trayectoria de iniciativas relacionadas con la interculturalidad en esta, no necesariamente aseguran una implementación óptima y comprometida de la enseñanza del mapudungun. Como se observa en la ELI, que cumplía ambos requisitos, la asignatura se imparte sin un gran impacto en el aprendizaje de los alumnos ni cambios en la cultura escolar del establecimiento. En cambio, pareciera tener mayor incidencia la actitud de los actores hacia la enseñanza de la lengua como un recurso de la escuela y su compromiso con la inclusión del mapudungun, tal como lo plantea García Marcos (1993), quien sostiene que las actitudes hacia la lengua influyen en los procesos de revitalización de esta.

Por otra parte, destaca también el apoyo de los directivos como un factor fundamental en la implementación de este sector curricular, de forma coherente con lo que concluye Treviño y otros (2012). Asimismo, se aprecia que el apoyo de otros docentes, como en el caso de la EB, es relevante para profundizar y transversalizar la presencia del mapudungun en el establecimiento. En los otros casos, la transmisión de la lengua descansa solamente en las educadoras tradicionales, lo que restringe las posibilidades de su aprendizaje solo a las instancias en que las educadoras ejercen su labor.

Otro factor relevado es la definición y el uso de algunos espacios de la infraestructura escolar como escenarios pedagógicos especiales para llevar a cabo prácticas de enseñanza de la lengua y cultura mapuche. 
La presencia de estos muestra una actitud positiva no solo hacia el conocimiento mapuche, sino que también hacia su forma de transmisión.

Considerando lo expuesto, los aspectos claves para alcanzar una adecuada implementación de cualquiera de las estrategias mencionadas son: i) cooperación y compromiso de los directivos y planta docente; ii) incorporación del educador tradicional en tanto docente que incluye sus saberes y estrategias metodológicas mapuche en su quehacer; iii) participación de la comunidad indígena no solo para efectos resolutivos (elección del educador), sino como fuente fundamental de conocimientos ancestrales que interactúa con la otra cultura; y iv) uso de espacios de significación cultural.

A partir de lo anterior, dado que la lengua se entiende como una práctica social, emergente y creativa, su revitalización escapa a cualquier iniciativa individual y adquiere sentido solo en la medida en que la comunidad completa asume esta tarea como propia.

\subsection{Competencia lingüística}

En el marco de la competencia comunicativa planteada por Hymes (1971), los educadores de los tres casos analizados declaran y evidencian una elevada competencia de mapudungun. Todos la adquirieron en contexto familiar y tres de ellos de manera simultánea con el castellano.

Considerando lo anterior, el grupo de educadores tradicionales representaría un sector de la población mapuche con características diferentes a la mayoría de esta, que manifiesta una competencia baja en mapudungun, siguiendo los planteamientos de Gundermann y otros $(2008 ; 2009)$.

Dentro del manejo de la lengua mapuche, la competencia discursiva oral aparece como la habilidad más desarrollada, puesto que es la práctica de transmisión ancestral por excelencia. El empleo de los diferentes géneros discursivos mapuche en el contexto escolar aporta al desarrollo de dicha competencia. Por su parte, tal como se evidencia en los resultados, la lectura y la escritura se asumen como competencias complejas, acentuadas por la falta de dominio de los grafemarios existentes. En este sentido, la escritura sería una habilidad funcional deseable para la enseñanza del mapudungun, al mismo tiempo que un instrumento concreto de difusión y desarrollo de la lengua, en la medida 
que los grafemarios fueran dominados y utilizados habitualmente por la población hablante.

Respecto al uso de la lengua mapuche en el contexto escolar, los tres casos se diferencian según las estrategias pedagógicas utilizadas por los educadores. Ello se grafica con claridad en la EB, en donde tanto los educadores comola profesora mentora promueven actividades orientadas a la práctica permanente del mapudungun. Aquí la oralidad asume un rol protagónico y la dupla pedagógica entiende que la revitalización de una lengua exige la interacción en dicha lengua, en tanto práctica social (Hymes, 1971). Esto lleva a señalar que si bien el uso del mapudungun en términos generales depende del contexto sociolingüístico, el empleo de este en el aula se incrementa en la medida en que el educador, junto al profesor mentor, genera posibilidades de interacción en esta lengua.

Lo anteriormente expuesto motiva la reflexión acerca del alcance que pueda tener la asignatura de Lengua Indígena en cuanto a lograr un bilingüismo en los estudiantes de las escuelas que la implementan en el país. Se estima que no es posible hacer recaer la responsabilidad de revitalizar el mapudungun en los educadores tradicionales o en las comunidades escolares donde trabajan, sin considerar la situación de vitalidad lingüística en los contextos más amplios que circundan a la escuela. El carácter no funcional y acotado a los espacios privados o ceremoniales del mapudungun hace improbable que se produzca un bilingüismo en los estudiantes, como el que se espera en los programas de estudio de esta asignatura.

Asimismo, resulta indispensable acompañar la tarea específica de enseñanza del educador con iniciativas tendientes al aumento de una actitud positiva hacia la lengua mapuche dentro de la comunidad, de manera de poder influir en los procesos de conservación y desplazamiento del mapudungun (García Marcos, 1993).

\subsection{Competencias interculturales}

El estudio de casos puso en evidencia que la enseñanza del mapudungun no puede escindirse de la enseñanza de la cultura mapuche, pues los elementos centrales de la lengua son precisamente aspectos de la cultura que son difícilmente transmisibles sin esta. Es por ello que tan importante como el dominio de la lengua es que los 
educadores tradicionales conozcan la historia, la vida cotidiana y la sociedad mapuche.

Este ámbito, que dice relación con la dimensión cognitiva de las competencias interculturales (Vilà, 2003), fue destacado por todos los actores como parte de las fortalezas de los educadores. Sin embargo, esta dimensión también abarca las relaciones entre las culturas dentro y fuera de la sala de clases. Gran parte de los esfuerzos de los educadores, sobre todo en contextos en que predomina la población mapuche, está centrado en expandir los conocimientos sobre el mundo mapuche a los estudiantes, realizando, en la práctica, clases de cultura.

Las otras dimensiones de la competencia intercultural, afectiva y conductual parecen expresarse dependiendo del contexto del establecimiento educacional y según el grado de diversidad étnica presente en la escuela.

Finalmente, se estima que las habilidades, actitudes y conocimientos relativos a la competencia intercultural se materializan en procesos y no en acontecimientos. En consecuencia, para ser investigados, sería pertinente utilizar metodologías que profundicen en estos ámbitos, tal como la etnografía escolar. 


\section{Bibliografía}

Acuña, M. (2012). Perfil de Educadores Tradicionales y Profesores Mentores en el marco de la implementación del Sector de Lengua Indígena. Serie $\mathrm{N}^{\circ} 1$ Educación e Interculturalidad; MINEDUC- UNICEF.

García Marcos, F. (1993). Nociones de sociolingüística. Barcelona: Octaedro.

Grosjean, F. (1982). Life with Two Languages: An Introduction to Bilingualism. Cambridge, Mass: Harvard University.

Gundermann, H., J. Canihuan, A. Clavería y C. Faúndez. (2008). Perfil sociolingüístico de comunidades mapuches de la Región del Biobio, Araucanía, los Ríos y los Lagos. Santiago: CONADI-UTEM. Documento de Trabajo.

Gundermann, H., J. Canihuan, A. Clavería y C. Faúndez. (2009a). "Permanencia y desplazamiento, hipótesis acerca de la vitalidad del mapudungun". RLA., 47, 37-60.

Gundermann, H., L. Godoy, J. Canihuan, E. Ticona, E. Castillo, A. Clavería y C. Faúndez. (2009b). Perfil sociolingüistico de lenguas mapuche y aymara en la Región Metropolitana. Santiago: CONADI-UTEM. Documento de Trabajo.

Gundermann, H., J. Canihuan, A. Clavería, C. Faúndez. (2011). “El mapuzungun, una lengua en retroceso". Atenea, 513, 111-131.

Hymes, D. (1971). Competence and performance in linguistic theory. Acquisition of languages: Models and methods (pp. 3-23). Huxley and E. Ingram. (Eds.) New York: Academic Press.

Loncon, E. y Martínez, C. (2011). Estudio levantamiento información, descripción y análisis de Planes y Programas Propios desarrollados por los establecimientos PEIB y CONADI..

Quidel, G. (2006). La enseñanza del mapudungun en comunidades mapuche, en el marco del PEIB MINEDUC-Orígenes. Cochabamba: Universidad Mayor de San Simón. 
Salas, A. [1992] (2006). El mapuche o araucano. Fonología, gramática y antología de cuentos. Fernando Zuñiga (ed.). Santiago: Centro de Estudios Públicos.

Sotomayor, C., Allende, C., Castillo, S., Fuenzalida, D. y Hasler, F., (2014). Competencias y percepciones de los Educadores Tradicionales Mapuche en la implementación del Sector lengua Indígena Mapuzugun. FONIDE $\mathrm{N}^{\circ}$ FT 11258 (Informe Final). Santiago, CIAE.

Strauss, A. y Corbin, J. (2002). Bases de la investigación cualitativa. Técnicas y procedimientos para desarrollar la teoría fundamentada. Bogotá: Universidad de Antioquia.

Treviño, E. et al. (2012). Educación para preservar nuestra diversidad cultural: desafíos de implementación del Sector Lengua Indígena en Chile. Santiago: Ministerio de Educación.

Vilà, R. (2003). El desarrollo de la competencia comunicativa intercultural en una sociedad multicultural y plurilingüe: una propuesta de instrumentos para su evaluación. En J. Perera (Ed.) (2003). Plurilingüisme i educació: els reptes del segle XXI. Ensenyarllengües en la diversitat i per a la diversitat. Barcelona: ICE (pp. 259 - 270).

Zúñiga, F. (2007). Mapudunguwelaymi am? '¿Acaso ya no hablas mapudungun?' Acerca del estado actual de la lengua mapuche. En Estudios Públicos, 105, 9-24. 